Post-print article information:

To cite the author's post-print version:

Sabri, Y. (2019) "In pursuit of supply chain fit", International Journal of Logistics Management, in press.

\title{
In pursuit of supply chain fit
}

\section{Abstract}

Purpose - This paper develops exploratory propositions and a conceptual framework on the interaction between organisational structure (decision-making centralisation and internal coordination) and the relationship between supply chain fit and firm performance.

Design/Methodology - Through a case study, two corporate groups with distinctive organisational structures were examined; both are undergoing a critical moment of changes to their top management and are reshaping their corporate and supply chain strategies. Data on decision-making centralisation, internal coordination mechanisms, supply, demand and innovation uncertainties, and supply chain strategies was collected from key respondents.

Findings - The analysis conducted suggests the need to consider the joint interaction between organisational structure and supply chain fit in offsetting the implications of a potential misfit on firm performance. Furthermore, the context-sensitivity of a supply chain is often overlooked, hence simply modifying supply chain strategy does not necessarily lead to a variation in firm performance.

Practical Implications - This research is of particular importance to most organisations in the testing times of uncertainty in the global landscape. It guides supply chain practitioners to better understand which elements of the organisational structure interact with the uncertainty of supply, demand and innovation.

Originality/value - This paper is one of the first to investigate the interaction between elements of organisational structure and supply chain fit, and identifies decision-making centralisation and coordination as the internal uncertainty factors that are most relevant to supply chain fit research. A conceptual framework has been built for future testing, in which 
the organisational structure moderates the relationship between supply chain fit and firm performance.

Keywords: Supply chain fit, supply chain strategy, organisational structure, uncertainty, abductive reasoning.

\section{Introduction}

The notion of fit became a central theme in supply chain research when Fisher (1997) proposed that superior performance can be achieved by matching innovative products (i.e., high demand uncertainty) with responsive supply chain strategy, and functional products (i.e., low demand uncertainty) with cost-efficient supply chain strategy. Chopra and Meindl described this type of match as the 'zone of strategic fit' (Chopra and Meindl, 2007, p. 46). Put simply, to achieve higher firm performance, organisations need to decrease environmental uncertainty by aligning their supply chain strategy with their competitive strategy, thus taking uncertainty factors into account in the design of supply chains (Flynn et al., 2010; Defee and Stank, 2005). Therefore, consistency between supply chain strategies and their design with regards to the environment becomes a fundamental idea in achieving supply chain fit (Stock et al., 1998; Wagner et al., 2012).

The cumulative evidence in the supply chain literature suggests that fit is positively related to a firm's operational performance (Stock et al., 2000; Hallavo, 2015) and financial performance (Wagner et al., 2012; Hallavo, 2015, Gligor 2017). Yet, the literature has provided mixed findings on the dichotomy of responsiveness versus efficiency, where the notion of designing purely responsive or cost-efficient supply chains was not supported in the findings of some studies (c.f. Selldin and Olhager, 2007; Hallavo 2015). Furthermore, recent research has pointed to a potential trade-off between the resources needed to achieve fit versus the expected benefits (Gligor, 2017). The higher the level of environmental uncertainty, the more challenging it becomes to achieve supply chain fit, hence more costly (Gligor, 2016). The inconclusive results in supply chain fit research can be due to terminology-heavy literature (Hallavo 2015, p. 71). Moreover, supply chain strategies result from multidimensional and conflicting uncertainties, which are often not fully investigated 
in the literature, and therefore the conceptualisation of supply chain fit can be daunting (Van de Ven et al., 2013, p. 403).

A second and equally important issue is that the supply chain fit literature usually adopts an outward look, which has led to few studies considering the internal environments of firms. Fit studies usually address three main elements: i) supply chain strategy and design, ii) environmental uncertainties, and iii) firm performance (Fisher, 1997; Lee, 2002). Yet, the environmental uncertainties addressed in supply chain fit research predominantly relate to product or market characteristics. For example, Qi et al. (2011) validated the moderating effects of demand, supply and technological uncertainty on the relationship between competitive and supply chain strategy, and firm performance. Hallavo (2015) investigated product demand, supply and technological uncertainty and their impact on organisational and operational performance. Wagner et al. (2012) investigated supply and demand uncertainty and extended the work of Fisher (1997) by introducing the notion of positive and negative misfit to reflect different degrees of the 'match'. Gligor (2016, 2017) investigated uncertainties of market and technological dynamism, technical complexity, product diversity and geographic dispersion.

The high research concentration on product uncertainty has left other internal uncertainties, as well as their impact on supply chain fit and firm performance, relatively unexplored. This could be because the notion of supply chain fit in Fisher's (1997) propositions, while providing ground-breaking insights, overlooks the role of firms' internal environment (Gligor, 2017; Prajogo et al., 2018). Not surprisingly, the role of organisational structure is also often overlooked in the supply chain fit literature. Organisational structure affects an organisation's strategic actions (Eva et al., 2018), and therefore investigating organisational structure is even more important in times of uncertainty and organisational change. Another reason is because of its positive impact on firm performance (Buttermann et al., 2008; Zheng et al., 2010; Gambi et al., 2015), particularly financial performance (Qi et al., 2017). Furthermore, firms that are organised in a way that allows them to deal primarily with stable markets may not perform as effectively in high-uncertainty environments, so do their supply chains (Nahm et al., 2003). 
The elements of organisational structure have been found to be positively related with developing a supply chain innovation capability (Daugherty et al., 2011), and resilience capability (Treiblmaier, 2018). Similarly, it impacts on supply chain performance (Kim, 2007). Furthermore, certain combinations of organisational structure and supply chain strategy will lead to variations in firm performance (Defee and Stank, 2005). In light of this discussion, whilst organisational structure has been investigated in a number of studies in a supply chain and logistics context, however, a comprehensive analysis on the interaction between organisational structure and supply chain strategies, uncertainties and performance is still missing in literature.

The present research attempts to bridge this gap in the supply chain fit literature by exploring how the level of centralisation of decision-making, the internal span of control, lateral relationships, hierarchy and authority interact with supply chain fit and firm performance. Organisational structure usually deals with 'how the tasks are allocated among organizational units and how decision-making authority is specified' (Stock et al., 1998, p. 43), as well as internal coordination mechanisms (Parthasarthy and Sethi, 1992). To that end, this research poses the question: How do the levels of decision-making centralisation and internal coordination of the organisational structure impact on the relationship between supply chain fit and firm performance? The research explores the organisational structure of two corporate groups passing through a critical moment of changing their top management. Supply chain fit (demand, supply and innovation uncertainties and supply chain strategies) are also investigated.

This study makes several contributions to supply chain theory and practice. Firstly, the research identifies decision-making centralisation and internal coordination as the most relevant internal uncertainty factors for supply chain fit research, since they help in offsetting the impact of a potential misfit on firm performance. Hence, the paper extends the findings of Gligor (2017) and Prajogo et al. (2018) by addressing the lack of research (in the supply chain fit literature) on the role of an organisation's internal environment. Secondly, the research develops a novel conceptual framework that provides a better understanding of the interaction between internal uncertainty factors and supply chain fit and enhancing firm performance. Thirdly, the research applies maximum variation guidelines to the selection of 
case studies (Patton, 1990; Flyvbjerg, 2011), as well as an abductive approach, which has helped in developing four exploratory propositions that guide supply chain researchers and practitioners in organisations that are experiencing environmental change to consider the potential joint effects of external/internal uncertainties and supply chain strategies on firm performance.

The paper begins with a theoretical background of supply chain fit research and its

findings, and examines the links with organisational structure, followed by the research design section. The findings are presented in Section 4, and the propositions and conceptual framework are discussed in Section 5. The theoretical contribution and managerial implications are discussed in the last section.

\section{Theoretical background}

\subsection{Supply chain fit: strategy, design and uncertainty factors}

Previous research emphasised the importance of the context-sensitivity of a supply chain (Melnyk et al., 2014) and the interplay with its design (e.g., Fisher, 1997; Lee, 2002; Farahani et al., 2014). Fit studies usually involve three variables: environmental uncertainty factors, response actions, and performance indicators. Uncertainty factors represent the situational characteristics of the environment to which the firm has to react through response actions. Fit is reflected in the level of performance that results from how a firm's strategy (and its design) deals with the uncertainty in its environment (Sousa and Voss, 2008).

The elements of supply chain fit that are addressed in the literature include, firstly, supply chain strategy and design: responsiveness and/or cost-efficiency strategies (Fisher, 1997; Lee, 2002; Selldin and Olhager, 2007); secondly, product and/or market-related uncertainties, that is, demand, supply, innovation and complexity uncertainty factors (Qi et al., 2011; Wagner et al., 2012; Hallavo, 2015; Morita et al., 2015; Gligor, 2016, 2017); and thirdly, their impact on firm performance in terms of flexibility, quality and cost (Stock et al., 1998; Selldin and Olhager, 2007), financial indicators, such as ROI, ROA and market share (Qi et al., 2011; Wagner et al., 2012; Gligor, 2016, 2017), and operational and organisational performance (Hallavo, 2015). However, some supply chain fit studies do not 
measure the impact on performance at all (Prajogo et al., 2018). A summary table that includes details on the supply chain fit literature is presented in Annex 1.

Early scholarly work on supply chain fit can be seen as comprising two complementary streams - one with a focus on matching both supply chain strategy and design to environmental uncertainty (Fisher, 1997; Lee, 2002; Defee and Stank, 2005), and another focusing on matching supply chain design to its strategy (Stock et al., 1998; Stock et al., 2000). In the second stream, Stock et al. (1998) developed a conceptual framework hypothesising the supply chain as an extended enterprise, and suggested that the right choice of certain combinations of strategy-structure-logistics practices can improve firm performance.

A seminal work by Fisher (1997) suggested that supply chains should be designed by taking into consideration the product's level of innovativeness. In his research, Fisher argued that superior firm performance can be attained by matching functional products (characterised by a low degree of innovativeness) with physically efficient supply chain strategies, and by developing a market-responsive supply chain for innovative products so as to overcome high demand uncertainty. Lee (2002) extended Fisher's work and introduced an 'uncertainties framework,' wherein the impact on the supply chain of both supply and demand uncertainties are considered.

Fisher's research triggered a number of studies on supply chain fit, some of which were supportive of his propositions, whilst others were not. Selldin and Olhager (2007) empirically tested these hypotheses and found that many firms adopt a blended responsivenessefficiency strategy. They challenged Fisher's proposition that a particular match leads to superior performance, and argued that there is no empirical evidence to support the notion of purely market-responsive or physically efficient supply chain strategies. Hallavo (2015) claimed that supply chain efficiency is not an alternative strategy to responsiveness, but rather a precursor. The findings of Qi et al. (2011) confirmed the contention that organisations do not take decisions on supply chain strategy as an 'either-or' choice. They concluded that in high-uncertainty environments, cost leadership and the focus on mainly lean capabilities do not lead to significant benefits in terms of firm performance. Rather, firms with cost leadership need to achieve a balance. Furthermore, they found that 
environmental uncertainty has a minor influence on decisions regarding supply chain strategy in the case of firms with a differentiation strategy that mainly need to focus on agile capabilities in all situations. This line of thinking was echoed in Gligor (2016), who argued that different levels of environmental uncertainty imply different levels of supply chain fit. As such, the higher the environmental uncertainty the more challenging (and expensive) it becomes to achieve supply chain fit. Hence, when firms operate in high-uncertainty environments, they need to develop agility capabilities in order to achieve supply chain fit.

Wagner et al. (2012) suggested that not all misfit configurations worsen firm performance. They introduced two novel misfit configurations - negative misfit (i.e., responsive supply chains with a low demand uncertainty), and positive misfit (i.e., efficient supply chains with high demand uncertainty). In their framework, firms with a positive misfit have a reasonably better financial performance compared to those with a negative misfit. Hence, if supply chain fit is not attainable or is likely to be very expensive, firms can choose to adopt a design that does not undermine their performance. Gligor (2017) extended the findings of Wagner (2012) and identified the environmental conditions in which firms benefit the most from fit. $\mathrm{He}$ found that in high-uncertainty environments, the gains (in terms of firm performance) from supply chain fit can be offset by the costs of the resources needed to maintain the fit. Moreover, he claimed that firms in low-growth industrial sectors benefit least from supply chain fit, and that they benefit more when offering a product with a low level of technical complexity. Rojo et al. (2016) identified ambidextrous environments (the ability to simultaneously explore opportunities and exploit competences) as enabling high supply chain fit (a measure of supply chain flexibility), whereby firms can accumulate valuable capabilities to enhance their performance.

In conclusion, supply chain fit research is becoming a central theme in the supply chain literature (Hallavo, 2015). Product and/or market-related uncertainties (namely demand, supply and innovation) are by and large the main environmental uncertainty factors addressed in supply chain fit studies thus far. The literature has evolved from favouring Fisher's (1997) propositions (Chopra and Meindle, 2007), or testing them (Selldin and Olhager, 2007; Wagner et al., 2012), to identifying how and when supply chain fit can be achieved, as well 
as the environmental conditions under which the propositions hold, what the capabilities needed are, and when the fit can be truly beneficial (Qi et al., 2011; Gligor, 2016, 2017).

The literature, meanwhile, has developed from merely focusing on structures (Stock et al., 1998, 2000) to incorporating supply chain environments, structure and strategies. Moreover, supply chain strategies are moving from the continuums mind-set to a complementarity of efficiency and responsiveness (Hallovo, 2015), and the configurations are moving from the fit/misfit dichotomy to a fit, positive and negative misfits (Wagner et al., 2012). Furthermore, recent studies (e.g., Prajogo et al., 2018) have called for research that considers the internal (i.e., intra-firm) environment in supply chain fit studies, which was overlooked in Fisher's (1997) model.

The vast majority of supply chain fit publications apply a survey methodology (e.g., Wagner et al., 2012; Gligor, 2016; Rojo et al., 2016). Quantitative approaches offer generalisable findings, but their prevalence has steered the field's growth in a positivist direction, leading to the acceptance of their findings without questioning their contextual suitability. So far supply chain fit literature depends mainly on testing theories rather than developing them, this can hinder theory generation of what is essentially a relatively new stream of research (Kovács and Spens, 2005). For this reason, the decision was taken to follow a qualitative approach in the present research.

\subsection{The role of the internal environment: organisational structure and supply chains}

Organisational structure is an important dimension of an organisation's environment (Zheng et al., 2010). Investigating organisational structure is particularly important in supply chain fit research because internal structures must be taken into account when developing supply chain strategies (Defee and Stank, 2005). In particular, the centralisation of decision-making has been found to support the building of organisational capabilities that strengthen supply chain resilience (Treiblmaier, 2018). Furthermore, certain elements of the organisational structure (namely decision-making centralisation and formalisation) have been found to be positively linked to supply chain innovation capabilities (Daugherty et al., 2011), while internal integration has been found to have a more significant impact on a firm's financial performance than external supply chain integration (Qi et al., 2017). 
Organisational structure usually deals with 'the division of tasks, the distribution of decision-making authority and the level of [internal] integration used' (Parthasarthy and Sethi, 1992, p. 98), and with 'how the tasks are allocated among organizational units and how decision-making authority is specified' (Stock et al., 1998, p. 43). Essentially, organisational structure is concerned with task allocation, administration, integration and control within the organisation (Child, 1972). Tools such as organisational charts and hierarchies are instrumental in understanding the organisational decision-making process (Christensen and Knudsen, 2010).

As already outlined, organisational structure can be conceptualised in various ways. This study is primarily concerned with the elements of organisational structure that relate to supply chain fit. As such, this paper has identified decision-making centralisation and internal coordination mechanisms for further investigation (Stock et al., 1998, 2000). Centralisation has been selected because it is considered a key environmental factor; the decision-making authority within individual firms influences the success of the entire supply chain (Defee and Stank, 2005; Daugherty et al., 2011). Centralisation is concerned with 'the degree to which decision making is concentrated at the upper level of management, with decentralization involving the dispersion of such authority throughout the lower levels of the organization' (Eva et al., 2018, p. 173). The more centralised the decision-making, the more it is held at the top levels of management (Treiblmaier, 2018). Hence, employees in highly centralised organisations may have less autonomy to make decisions regarding, for example, supplier selection. Internal coordination has been selected for investigation because in order to address the uncertainty in supply chain strategy and design, organisations need a high level of interaction and coordination, both internally and externally (Stock et al., 1998; Stock et al., 2000), which facilitates information sharing, the deployment of resources and data accessibility across the supply chain (Defee and Stank, 2005).

\subsection{The evolution of supply chain fit}

As a multidisciplinary field, it is common for supply chain research to extensively borrow theoretical perspectives from various disciplines. The concepts of organisational and strategic management are therefore prevalent, especially contingency and configurational 
approaches that were introduced to organisational studies in 1965 by Joan Woodward, who investigated enhancing firm performance by examining the firm's environmental factors. These concepts also appeared in the business network research of Håkansson and Snehota $(1989,2006)$, who found that organisations are not isolated islands, but are embedded in a web of interrelated structures and networked relationships.

The contingency theory hinges on the proposition that there is no optimal method to design an organisation. Rather, to achieve superior performance, organisational designs should be contingent on the factors that are embedded within their internal and external environments (Fry and Smith, 1987; Doty et al., 1993). The premise of the contingency approach is anchored in establishing a fit between a firm's structure and its environment (Drazin and Van de Ven, 1985).

The notion of fit in the organisational management literature (e.g., Lawrence and Lorch, 1967; Khandwalla, 1972; Mintezberg, 1979) emphasises the consistency between an organisation's environment and its structure that is needed in order to enhance environmentstructure fit. Organisations can decide on the configuration/structure that is most consistent with their environment to sustain improved performance levels. Otherwise, organisations can be forced to trade off their situational fit against the internal consistency of their structures. Environment-structure fit research usually investigates the relationships between two variables - a bivariate uncertainty factor and a response action - and assumes a static situation.

On the other hand, the literature on strategic management considers fit as an alignment or matching of a firm's strategy to its environment (Miles and Snow, 1978). Zajac et al. (2000) argued that environment-strategy fit is a dynamic and multidimensional phenomenon, thus it can be hard to measure or predict, as in complex longitudinal studies. Moreover, investigating the association between multi-independent variables (multivariate) and a dependant variable can complicate data collection and analysis (for example, investigating how the associations between product innovativeness, firm size and employees skills can impact on firm performance). Figure 1 depicts the outlined differences between structural and strategic fit. 
The contingency approach has been subject to multiple revisions in response to the strong criticism it has faced. For example, Drazin and Van de Ven (1985) argued that contingency models are characterised by 'instability and confusion,' and that they have been studied with an 'implicit pool of assumptions.' This confusion is mainly due to the absence of an explicit conceptualisation of fit and the lack of a clear identification of its underlying concepts, which has led to its use in the literature as an axiom. In other words, since one cannot explicitly identify the concept, various assumptions are inevitably made along the research process. Conceptualisation can be even more challenging if the sought-after fit concerns multiple horizontal units, as in the case of a supply chain. A review by Kathuria et al. (2007) found that research on achieving alignment between horizontal units, for example in the supply chain, is relatively sparse.

Figure 1. Different perspectives of fit

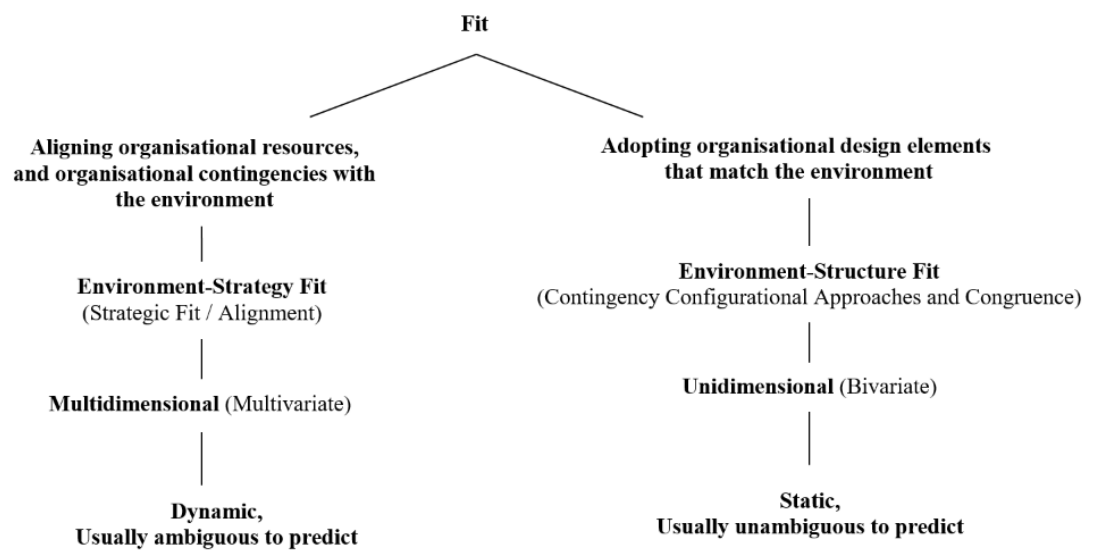

Adapted from: Miles and Snow (1978), Zajac et al. (2000) and Van de Ven et al. (2013)

Considering the complexity and multi-dimensionality of real-world uncertainties, it is obvious that the absence of a proper conceptualisation of fit creates a challenge in terms of testing it empirically (Van de Ven et al., 2013). To overcome this issue, Van de Ven and Drazin (1985) put forward three different approaches for identifying and conceptualising fit - selection, interaction, and systems. The selection approach suggests matching the environment to structure. Interaction considers the effects of interaction, and is concerned with the effects of pairs of environmental factors and structure on performance. The systems 
approach, meanwhile, suggests fit as an internal consistency of sets of environmental factors, structure elements and performance.

In response to the criticism, the so-called structural contingency theory was developed, which essentially merged the configurational and contingency approaches. The configurational approach, or 'multi-contingency perspective' (Miller, 1987) was introduced to mirror the real world by capturing the multiple uncertainties that organisations deal with. The main criticism of configurational contingency approaches when dealing with complex networks and systems is that they do not offer strong empirical evidence of the relationship between fit and performance.

Fit can also be regarded from the lens of institutional theory as an isomorphism phenomenon (DiMaggio and Powell, 1983), wherein organisational forces and institutional pressure between firms result in homogeneity (i.e., organisations start to resemble each other). Isomorphism is considered a constraint to achieving fit, since the inter-organisational pressure can cause organisations to resemble each other regardless of the peculiarities of their environments (Gammeltoft et al., 2012).

The above-outlined different underlying fit rationales in the literature are synthesised in Table 1.

Table 1. Underlying fit rationales in the literature

\begin{tabular}{|c|c|c|c|c|c|}
\hline \multicolumn{2}{|c|}{ Fit Scope } & \multirow[t]{2}{*}{ Fit Rationale } & \multirow[t]{2}{*}{ Fit Concept } & \multirow[t]{2}{*}{ Theoretical Lens(es) } & \multirow[t]{2}{*}{ Source } \\
\hline SG & SC & & & & \\
\hline & $\bar{\checkmark}$ & $\begin{array}{l}\text { To enhance organisational } \\
\text { effectiveness }\end{array}$ & $\begin{array}{l}\text { Establishing a fit between a firm's structure and its } \\
\text { environment. As such, fit is achieved through } \\
\text { consistency between internal organisational design } \\
\text { elements and the external environment }\end{array}$ & Contingency theory & $\begin{array}{l}\text { Lawrence and Lorch, } \\
\text { (1967), Khandwalla, } \\
\text { (1972), Mintzberg } \\
\text { (1979) }\end{array}$ \\
\hline & $\checkmark$ & $\begin{array}{l}\text { To advance and achieve } \\
\text { superior firm performance }\end{array}$ & $\begin{array}{l}\text { There is no optimal way in designing an organisation. } \\
\text { Organisational design is contingent on different } \\
\text { contextual uncertainty factors embedded within their } \\
\text { external and internal environment }\end{array}$ & Contingency theory & $\begin{array}{l}\text { Fry and Smith (1987), } \\
\text { Doty et al. (1993) }\end{array}$ \\
\hline & $\checkmark$ & $\begin{array}{l}\text { To incorporate real life } \\
\text { complex multiple } \\
\text { contingencies in } \\
\text { organisational studies }\end{array}$ & $\begin{array}{l}\text { Fit is multidimensional and need proper } \\
\text { conceptualisation. The multiple contingencies firms deal } \\
\text { with should be considered in research }\end{array}$ & $\begin{array}{c}\text { Structural Contingency } \\
\text { Theory } \\
\text { Configurational } \\
\text { Contingency Approach }\end{array}$ & $\begin{array}{l}\text { Drazin and van de Ven } \\
\text { (1985), van de Ven } \\
\text { and Drazin (1985), } \\
\text { Miller (1987), van de } \\
\text { Ven et al. (2013) }\end{array}$ \\
\hline$\checkmark$ & $\checkmark$ & $\begin{array}{l}\text { To align (match) strategy to } \\
\text { environment and internal } \\
\text { organisational contingencies }\end{array}$ & $\begin{array}{l}\text { Fit is multidimensional and deals with multiple } \\
\text { relationships, dynamic and ambiguous phenomenon }\end{array}$ & Dynamic Strategic Fit & $\begin{array}{l}\text { Miles and Snow } \\
\text { (1978), Venkatraman }\end{array}$ \\
\hline
\end{tabular}


(1989), Zajac et al.

(2000)

To manage institutional pressure

To enhance firms competitive position in the market
Managing isomorphism institutional pressure which might direct organisations to resemble each other regardless the peculiarities of their environment

Business performance depends on the firm's position in the industrial structure (i.e. external market), dynamics of the relationship and the power structures between the firm and the market
Institutional Theory

Isomorphism Pressures

Network Theory Industrial Marketing and Purchasing Group
Di Maggio and Powell (1983), Gammeltoft et al. (2012)

Håkansson and Snehota $(1989,2006)$

SG: environment-strategy fit

SC: environment - structural fit

\section{Methodology}

\subsection{Research design}

Case study research is a powerful methodology for theory testing, generation and elaboration, since it helps in interpreting the concepts in a specific context, instead of examining their intensity or frequency (Ketokivi and Choi, 2014). Furthermore, it provides greater exploratory depth (Meredith, 1998) than other methodologies, and is appropriate for the present paper, given its context-dependent nature (Yin, 2014) — what Flyvbjerg (2001) refers to as the 'primacy of context.' The case study approach in supply chain research can have certain limitations, in relation to the networks' complexity and dynamism, which can cause difficulty in identifying boundary settings and cross-examining findings (Halinen and Törnroos, 2005).

The research process for this paper started when an observation emerged from the data analysis of an earlier study of two corporate groups that had distinctively different environments. However, the way they managed and configured their supply chains was similar, and although the previous management of the two groups had not put much effort to achieve supply chain fit, their financial performance levels were high. These observations seemed to be not completely in line with the concepts of contingency theory, and therefore a decision was made to further investigate this observation by following an abductive research process.

Abduction was developed by Charles Sanders (Santiago) Peirce as an intuitive research approach to theory generation. It starts with unexpected real-life observations that represent 
an irregularity to the interpretations provided by available theories, and which therefore need further investigation. The abductive research process allows researchers to form new theoretical concepts and frameworks (Meyer and Lunnay, 2013), and usually ends with their proposing exploratory hypotheses/propositions that need further testing in a supply chain empirical setting (Kovács and Spens, 2005; Lawrence et al., 2018). As a multifaceted reasoning approach, abduction does not have a single definition - it was referred to sometimes as 'retroduction' and sometimes as a 'hypothesis' in Peirce's writings. For the sake of simplicity, this paper follows a definition put forward by Peirce himself in 1903, according to which abduction is '...the process of forming an exploratory hypothesis' (Roozboom, 1997).

The present research process embraces the guidelines provided by Kovács and Spens (2005), as depicted in Figure 2. It was apparent early on that there were distinctive organisational structures in use in the corporate groups under study. Therefore, the potential role of organisational structure - as an environmental uncertainty factor- emerged as an important lead, and this created an opportunity to suggest exploratory propositions regarding supply chain fit and firm performance. It was necessary to return to the literature to review previous studies on organisational structure/decision-making and how these factors link to supply chain and firm performance. Subsequently, additional interviews were conducted to generate a complete picture of the corporate groups' organisational structures, lateral relationships, hierarchy and span of control.

Figure 2. Abductive research process 


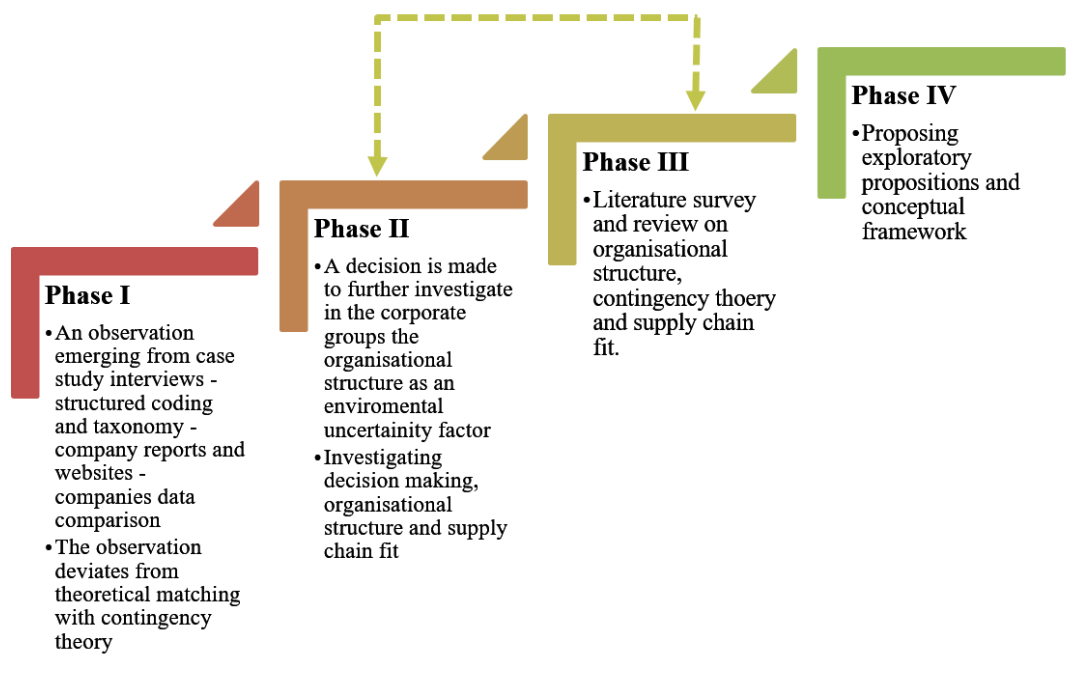

\subsection{Case selection criteria}

The selection criteria were guided by the need to identify information-rich cases. The main case study incorporated Patton's (1990) and Flyvbjerg's (2011) guidelines of maximum variation between cases, i.e., cases displaying great diversity in their characteristics, which usually leads to high-quality descriptions and the identification of patterns of uniqueness. Prior to initiating the abductive research process, the case selection criteria were carefully reviewed so that the cases would be appropriate to capture the elements of supply chain fit. Hence, this study's selection criteria incorporated Zajac et al.'s (2000) guidelines, according to which the ideal empirical context in which to examine the notion of fit is when the studied organisations face changing environmental conditions that trigger strategic change.

The case selection criteria of the main study were as follows: the organisations should have local and global supply, production and distribution networks, and their environments should reflect a multitude of uncertainty factors (e.g., industrial sectors, product characteristics, company sizes and location). Following Zajac et al.'s (2000) guidelines, a further criterion for this study was put forward, namely that the organisations should be going through a phase of strategic change and should be experiencing changing environmental conditions. Furthermore, to ensure geographical proximity to the research team and direct access to key executive-level respondents, the organisations had to have headquarters in Europe. 
Two corporate groups, with a total of 10 subsidiaries, were identified using the aboveoutlined criteria. They are headquartered in Italy and in Sweden, and have substantially different business cultures and organisational structures. The first corporate group (TOOL) is a leading manufacturer of high-technology tools, whilst the second (CARE) is a leader in the healthcare and personal-care sector. The two corporate groups have different environments and organisational structures, which permitted cross-case comparisons. Both corporate groups are undergoing critical top management change, and are reshaping their operational, corporate and supply chain strategies.

\subsection{Data collection and analysis}

In order to capture supply chain fit, the present research adopted the conceptualisation provided in previous studies (c.f. Qi et al., 2011; Wagner et al., 2012). As regards the elements of supply chain strategy, supply chain responsiveness was conceptualised by asking questions regarding delivery modes and reliability, manufacturing and inventory buffers, responses to unpredictable demand, and the rate of new product launches. Supply chain efficiency was conceptualised by asking questions regarding manufacturing process improvements, operational efficiency, product cost reduction and pricing. As regards external uncertainty factors, the questions were about the uncertainty of supply, demand and innovation (product life cycles, variants, forecast accuracy, location and number of sales points, rates of product innovation, rates of customer requirements change, easiness of finding suppliers, suppliers consistently meeting quality, and delivery requirements).

As regards internal uncertainty factors, the questions related to organisational structure followed the conceptualisation provided by Parthasarthy and Sethi (1992), Nahm et al. (2003) and Daugherty et al., (2011); as such, they concerned the existence of predefined rules and procedures, the number of layers in the hierarchy, the level of autonomy and locus of decision-making, and the level of internal coordination and integration.

Based on the above-outlined conceptualisation, the interview questions and protocol were developed. Embracing the abductive inference process, data were collected through semistructured interviews in order to allow the respondents to introduce new concepts that could help generate exploratory propositions (Meyer and Lunnay, 2013). Around 6-7 interviews were conducted per organisation (in English) with executive-level respondents, each lasting 
between 60 and 75 minutes. The respondents were asked to identify the product families that are most critical to their financial performance. Three CARE products and one TOOL product family were identified.

In order to ensure knowledgeable views on supply chain strategies and external uncertainties, the criteria for the selection of respondents were guided by the depth of their involvement in strategising and managing supply chains. In order to capture the dynamic environmental change dimension, the selection criteria targeted supply chain executives who had taken their positions prior to the top management changes and were still involved with the new corporate leadership in strategising the changes. In order to capture the internal uncertainty dimension, the selection criteria targeted senior-level executives who were responsible not only for supply chain management in the subsidiary companies but also for leading group-level projects and the strategizing of supply chains for critical product families. These outlined selection criteria of respondents are in line with the guidelines provided by Aguinis and Solarino (2019) for choosing respondents who have deep knowledge on a firm's strategies and are able to provide information on the dynamics between the different hierarchy levels in the organisation (termed 'elite informants').

An initial contact was made with the two groups in order to identify potential executivelevel respondents (CARE through email correspondence with the head of the supply chain, and TOOL through a face-to-face meeting with the group's $R \& D$ and academic relations general manager). Two key respondents who met the selection criteria were identified CARE's group supply chain \& planning head, and TOOL's vice president for supply chain management. The interview data were complemented by secondary data on the organisation, and the new leaders' strategies for change were found from internal documents, annual reports and company websites. The data collection is depicted in Table 2.

To ensure qualitative research rigour and reliability, the questions were sent beforehand the interview to the respondents (mentioning the possibility of addressing follow-up questions). The interviews were audio-recorded, transcribed and then cross-checked with the respondents. In addition, an external researcher helped verify the transcripts. Follow-up emails and/or phone calls were also used to clarify any outstanding issues. Thematic coding 
using a MS Excel spreadsheet was performed for the data analysis, where verbatim codes were grouped into categories, which helped generate conceptual themes.

\section{Findings}

\subsection{CARE: Organisational and supply chain overview}

CARE is a corporate group with six subsidiaries and is active in the healthcare, childcare and personal-care sectors. The group has recently been experiencing major changes in its business model and management style, leading to a review of its operational and supply chain strategies. Furthermore, the group is undergoing a major restructuring, transitioning from a family-owned group to a publicly listed one. CARE recently deployed an internationalisation plan to penetrate new markets, and established facilities in Mexico, Russia, India and the USA. This expansion has complicated CARE's supply chain in terms of distribution, inventory management, planning and supply management. Moreover, due to the 2008-9

Table 2. Data collection

\begin{tabular}{|c|c|c|}
\hline & CARE & TOOL \\
\hline Respondents & Group Supply Chain \& Planning Head & $\begin{array}{l}\text { Vice President for Supply } \text { Chain } \\
\text { Management }\end{array}$ \\
\hline Location & Italy (HQ) - branches in 24 countries & Sweden (HQ) - branches in 14 countries \\
\hline No. of subsidiaries & 6 & 4 \\
\hline Turnover & 1,415 million Euros & 3,010 million Euros \\
\hline Sector & Healthcare products & Engineering Technology \\
\hline Number of employees & 6,500 & 19,000 \\
\hline $\begin{array}{l}\text { Field visits by } \\
\text { researchers }\end{array}$ & 1 & 3 \\
\hline Secondary data used & $\begin{array}{l}\text { Financial reports }(2015 \text { - 2016), internal } \\
\text { documents and website }\end{array}$ & $\begin{array}{l}\text { Annual reports }(2014,2015,2016) \text { and } \\
\text { website }\end{array}$ \\
\hline
\end{tabular}

economic crisis that severely impacted the Italian market (considered its main market), CARE has been focusing on international markets, especially the US (its second biggest market after Italy). This international expansion and management transition has been accompanied by a change in CARE's corporate strategies, leading to the initiation of cost reduction and performance improvement projects.

CARE's new CEO is from another major Italian group. The mission of CARE's new leadership is to enhance the group's worldwide presence, build an organisational structure that suits the new business model, and effectively manage the change process, which it hopes will eventually enhance CARE's competitiveness in the market. The group usually has 
medium-term contractual agreements with its suppliers and retailers. These dyadic relationships are usually managed by CARE, as a focal actor in the network and one which possesses the strongest bargaining position. CARE continuously negotiates its purchasing policies and inventory visibility with its suppliers, and moves some of its inventory to suppliers' premises. It reviews supplier performance every three years.

\subsection{TOOL: Organisational and supply chain overview}

TOOL is a publicly listed corporate group comprising four subsidiaries. Over time, it has established a stable management style that is characterised by little hierarchy (i.e., it resembles a flat organisation). TOOL has just experienced changes to its top management, and has recently appointed a new CEO. The group has initiated a business expansion and is aggressively acquiring competing brands. Some of the newly acquired brands remain individually managed, having planning and supply chain processes that are separate from those of the group. Following the completion of the recent acquisitions, TOOL has taken over the international facilities of the acquired brands and has decided to shut down some of its distribution centres in order to save on costs. TOOL regularly hires experts in various fields to help improve business performance, but these experts appear to be working in silos; meanwhile the top management is making efforts to enhance internal coordination.

The design of TOOL's downstream supply chain depends on the market location. For example, the group serves the European market through direct sales to individual customers, whereas US customers are usually served through external distributors. TOOL depends on external carriers and distributors for product delivery, and the downstream chain is characterised by high responsiveness and fast 24-hour delivery. This limits the choice of carriers and thus the possible reconfiguration of the supply chain.

TOOL's upstream supply chain is internationally extended, including raw material suppliers from Asia (mainly China), as well as the USA and Europe (mainly Sweden). Due to the particular characteristics of its high-tech products, and the criticality of raw material extraction, which requires major long-term investments, TOOL relies on long-term contractual agreements with its suppliers. This results in TOOL having strategic dyadic interorganisational relationships with the few suppliers that can meet its quality requirements. 


\subsection{Organisational structure}

CARE's organisational structure, as depicted in Figure 3, is hierarchal and characterised by a high degree of centralisation of decision-making, specifically at the level of group CEO, with the decision-making process supported by a team of functional managers who form working sub-functional teams and design cross-functional projects. CARE initiates crossfunctional projects involving members from different departments, and this has helped it overcome the challenges of an organisational structure that is characterised by a long chain of command and a narrow span of control. As CARE's respondent elaborates: Each product project has a project manager and a project team, a group of people from different functions that are involved. This approach enhances internal coordination and thus lateral intraorganisational relationships. There is a focus on developing and implementing internal coordination mechanisms as an enabler of the group's transformation process. The rapid changes and the eagerness to transform the group from a family-owned model to an AngloSaxon one (by engaging external investors and starting to sell company shares) have resulted in a number of improvement projects and have enhanced internal coordination and integration. As elaborated by CARE's respondent: For the supply chain, he [the new CEO] asked us to change completely the mind-set and to put even more aggressive objectives. So we tried to change our way of doing things. 
Figure 3. Organisational Structure - CARE

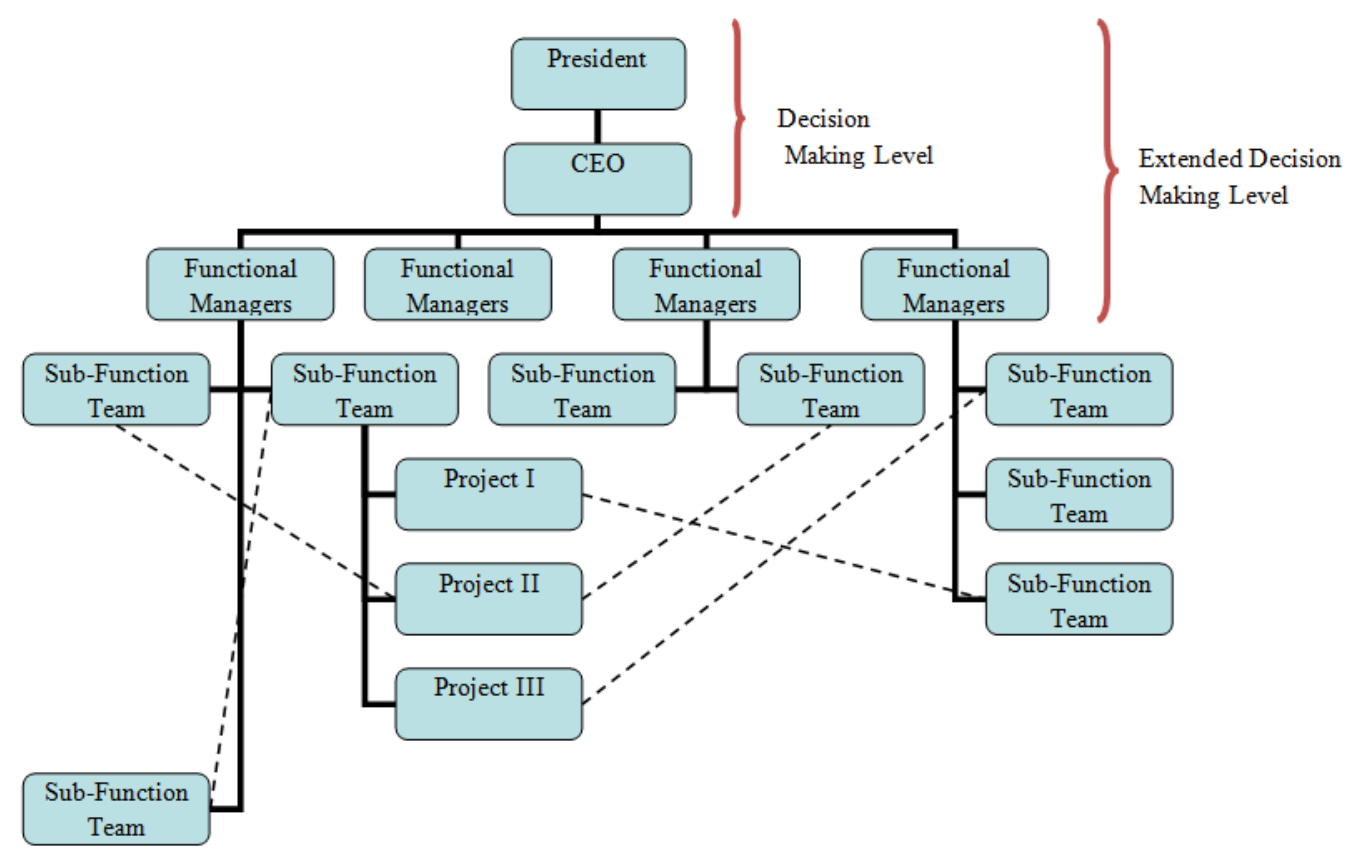

Figure 4. Organisational Structure - TOOL

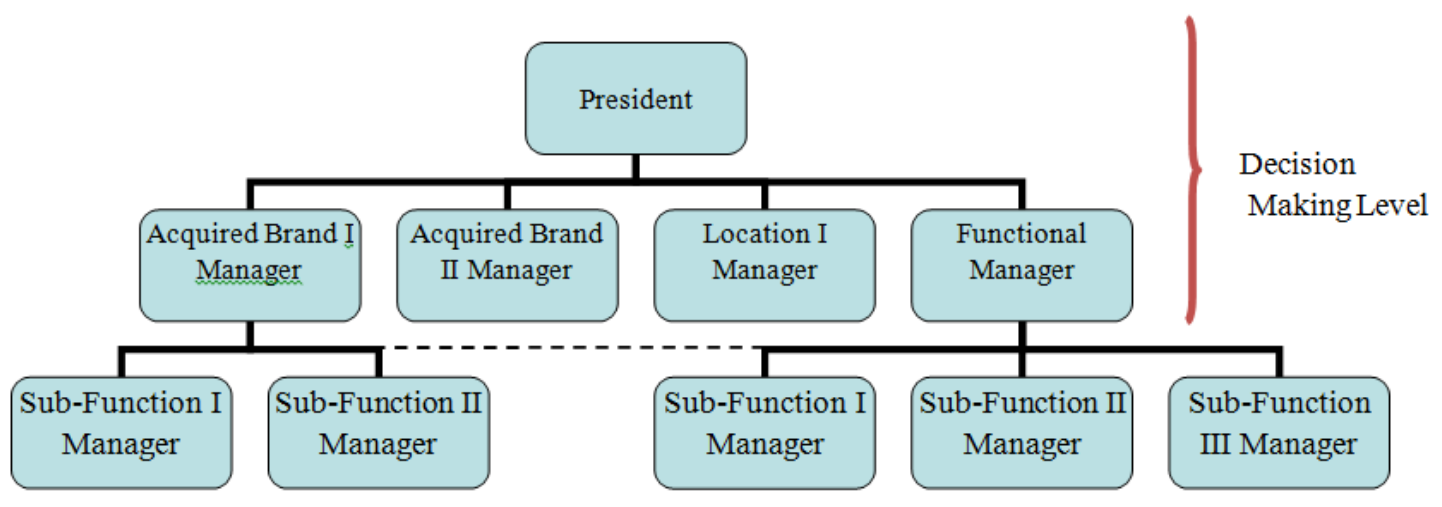

Meanwhile, in TOOL's organisational structure (shown in Figure 4), decision-making spans the CEO and top manager level, with an absence of cross-functional teams and a poor integration between the newly acquired brands and the parent company. TOOL has a rigid horizontal differentiation, and departments often work in silos, which makes the organisation less flexible than it could be and results in a low level of coordination of lateral intraorganisational relationships. As TOOL's respondent admits: We are very much in silos. 
In TOOL, which is more inclined towards a Nordic model (egalitarian decision-making and small income disparities), the pace of change implementation is slower, with prolonged discussions of matters awaiting conclusive decisions. This was illustrated by the use of the phrase 'ongoing discussions' twelve times in just one interview with TOOL's respondent, in reference to the decision-making situation. TOOL's decision-making tends to be based on internal situational factors, not on the external market or on product-related factors. Its management style is sporadic at the unit level, but it is more structured at the group level. For example, individual businesses and production units have the flexibility to make their own operational decisions (e.g., about production capacities and scheduling), whereas strategic decisions (e.g., where to produce, how to improve production and new product development) are managed more collectively at the top management level. The organisational structure of each group is summarised in Table 3.

Table 3. Organisational structures

\begin{tabular}{|c|c|c|c|c|}
\hline & Centralisation & Formalisation & $\begin{array}{l}\text { Vertical and Horizontal } \\
\text { Differentiation }\end{array}$ & Internal Coordination \\
\hline CARE & $\begin{array}{l}\text { - Centralised decision- } \\
\text { making at CEO and } \\
\text { president level } \\
\text { - Long chain of command } \\
\text { - narrow span of control }\end{array}$ & $\begin{array}{l}\text { - High } \\
\text { formalisation }\end{array}$ & $\begin{array}{l}\text { - Loose (flexible) } \\
\text { horizontal } \\
\text { differentiation } \\
\text { - Low specialisation } \\
\text { - Hierarchical }\end{array}$ & $\begin{array}{l}\text { - Highly dynamic internal } \\
\text { coordination level } \\
\text { between intra- functions } \\
\text { - Multiple cross- } \\
\text { functional projects }\end{array}$ \\
\hline TOOL & $\begin{array}{l}\text { - Decentralised decision- } \\
\text { making } \\
\text { - Short chain of command } \\
\text { - Wide span of control }\end{array}$ & $\begin{array}{l}\text { - High } \\
\text { formalisation }\end{array}$ & $\begin{array}{l}\text { - Rigid horizontal } \\
\text { differentiation } \\
\text { - High specialisation } \\
\text { - Flat Hierarchy }\end{array}$ & $\begin{array}{l}\text { - Low coordination levels } \\
\text { between intra-functions } \\
\text { - Experts working in silos }\end{array}$ \\
\hline
\end{tabular}

\subsection{Supply chain fit}

\subsubsection{Supply, demand and innovation uncertainty}

Two of the three examined CARE product families have growing market shares, a frequent rate of new product development ("...we renew our product range very often”), and a medium product lifecycle. The third product family has a longer lifecycle and fewer new product developments, since it is considered a functional product. Due to the high seasonality of the majority of its innovative products, CARE renews its product range frequently — some every year and others every few months - with high product variation and differentiation. As CARE's respondent notes: We have a big issue in terms of forecasting [...] inventory and 
synchronisation of the warehouses. Moreover, CARE offers a few functional products whose designs have changed little over the years, except for the external packaging. To add to the challenges, the high seasonality of its products means different timelines in different markets: Every country has a different requirement $[\ldots]$ Now we ask our central warehouse to prepare the goods in a lot of different ways. This leads to uncertainty in forecasting demand and creates supply-side risks. Therefore, greater supply chain integration is needed to absorb these challenges. CARE has established collaborative mechanisms with its suppliers that have helped it to decrease supply uncertainty: We analyse and optimise with our suppliers the mean ordering quantity of the raw material. CARE has also implemented quality procedures to ensure higher-quality products and service. The goal is to reduce product lead time and increase product availability, while reducing the stock of finished products in inventory.

The portfolio of TOOL's products is broadly functional and in a stable phase in the market. Due to their nature as high-technology engineered tools, TOOL's products have considerably longer lifecycles with low design variation and little change over the years, which entails low innovation uncertainty. This, combined with material and supplier criticality, leads to a low frequency of supplier changes. As explained by TOOL's respondent: There are not many suppliers in the market who can provide us with this sort of material compositions.

TOOL is trying to establish higher degrees of flexibility to enable different products to be manufactured in different plants, which requires more collaboration and synchronisation in production area decision-making. However its products are quite fragmented, as TOOL's respondent admits: [acquired brand] is not really integrated yet ... they still manage their own production units. TOOL recruits experts who use sophisticated planning and forecasting techniques, and this has resulted in a decrease in demand uncertainty. Forecasting and planning are performed over a long, five-year horizon, but forecasting is reviewed every month and planning, provisionally, every 18 months. Through a centralised production plan, which is consolidated using data from various production plants, the production plants specify their production capacity for each stock-keeping unit. TOOL uses reversed logistics networks for product recycling, which helps it decrease supply risk by retaining critical raw materials that are used in certain products. TOOL's policy of Go-To-The-Market 24-hour 
delivery has led to a solid base of loyal customers, which has helped the group to predict demand.

\subsubsection{Supply chain strategy: efficiency and responsiveness}

Modifying the supply chain structure and strategy is usually justified when the market is moving. Supply chain strategies are blended, for example, TOOL's supply chain is designed to be cost-efficient on the upstream side by establishing partnerships with few suppliers, but it is very responsive on the downstream side and offers a 24-hour product delivery with high service level.

CARE's new leadership has concerns regarding efficiency in the logistics, inventory and planning areas. The main objective is to improve the efficiency of inventory management and material/product handling, and to that end, the group is investigating the feasibility of using third-party logistics (3PL). CARE initially owned all its warehouses in Italy, Spain, Portugal, the UK and Brazil. Recently, it has shut some warehouses to reduce distribution

costs, and has started using 3PL services and the facilities of its subsidiaries; meanwhile, European distribution has been centralised in two distribution centres in Italy. This situation has presented certain challenges, since customer requirements and behaviour differ across European countries with regards to packaging and product specifications. As a result, CARE has had to acquire knowledge about various logistics activities that it did not conduct before. However, it has recently started reconsidering the offshoring agreements due to the risks associated with the long distance and the difficulty in dealing with foreign suppliers. This situation also limits flexibility because decisions regarding any needed supply chain reconfiguration require often lengthy negotiations.

\section{A framework for supply chain fit}

The consolidated financial data for CARE shows a sales increase of 1.5 per cent as compared to the previous year, and 18 per cent from two years earlier, with a net profit increase of 2.5 per cent (CARE Financial Report, 2016). According to Fisher's (1997) original work, a business like CARE, with high innovation uncertainty and demand uncertainty, needs a responsive supply chain. However, the group has adopted a cost-efficient upstream and downstream supply chain strategy. This creates a supply chain misfit and should have caused 
a decline in financial performance, but the data for financial as well as operational performance shows consistent improvement over the years.

TOOL with its high supply uncertainty and low innovation uncertainty and demand uncertainty, needs a cost-efficient supply chain to achieve fit. However, the group has a blended upstream supply chain strategy and responsive downstream supply chain. This also creates a supply chain misfit and should have affected TOOL's financial performance. TOOL's 2016 Annual Report reveals a 3.5 per cent increase in net profits, as compared to the previous year, despite a drop in revenue of 5 per cent. Table 4 depicts the findings in terms of supply chain strategy and supply, demand and innovation uncertainty levels.

Table 4. Supply chain strategy and external uncertainty factors

\begin{tabular}{|c|c|c|c|c|c|}
\hline & $\begin{array}{l}\text { Supply chain } \\
\text { strategy }\end{array}$ & $\begin{array}{l}\text { Supply } \\
\text { uncertainty }\end{array}$ & $\begin{array}{l}\text { Demand } \\
\text { uncertainty }\end{array}$ & $\begin{array}{l}\text { Innovation } \\
\text { uncertainty }\end{array}$ & $\begin{array}{l}\text { Fit/Misfit* } \\
{ }^{*} \text { Fisher (1997) }\end{array}$ \\
\hline TOOL & $\begin{array}{l}\text { Blended: } \\
\text { Cost-efficient } \\
\text { upstream, responsive } \\
\text { downstream }\end{array}$ & High & Low & low & Misfit \\
\hline CARE & $\begin{array}{l}\text { Cost-efficient } \\
\text { upstream and } \\
\text { downstream }\end{array}$ & Low-to-medium & High & High & Misfit \\
\hline
\end{tabular}

Based on the outlined analyses, the following section discusses four exploratory propositions developed to interpret the relationships between supply chain strategy, supply, demand and innovation uncertainty and firm performance.

CARE's targeted markets emphasise frequent changes of product design. The group mitigated this demand and innovation uncertainty by instituting a faster decision-making process that is more flexible and more responsive. Around 80 per cent of CARE's externally supplied components come from China, and this entails uncertainty as regards offshoring issues. However, the supply market is considered non-critical due to the abundance of alternative suppliers and the availability of reasonable pricing. CARE's centralised decisionmaking, coupled with its high demand and innovation uncertainty, have forced it to initiate many improvement projects to cut costs, which have resulted in improved efficiency and operational performance. As noted by CARE's respondent: We don't have big issues in terms 
of efficiency in our production in Italy because we already worked in the past in order to have a big [better] flexibility and elasticity in the production.

Centralised decision-making has allowed CARE to foster strategic agreements with selected key suppliers and enjoy considerable bargaining power and a strong position within its supply chain, which has allowed it to direct negotiations and manage upstream and downstream dyadic relationships to suit its business requirements. That has led to an enhanced performance. As noted by CARE's group supply chain \& planning head: We never had a negative performance, so we are still in a positive situation in terms of turnover.

P1. With a cost-efficient supply chain strategy, demand uncertainty and innovation uncertainty are negatively related to firm performance. The level of decision-making centralisation within the organisational structure has a moderating effect.

Decision-making in TOOL is decentralised, and its management style promotes intense and prolonged discussions between different layers of management before a decision can be arrived at. TOOL has relatively few suppliers due to the material and technical criticality, and this means high supply uncertainty, a situation that has imposed some restrictions on its improvement projects. Furthermore, decentralisation has resulted in fragmented decisionmaking, which is not conducive to performance improvement. As noted by TOOL's Vice President for Supply Chain Management: We are looking into improving our performance and we're having a discussion right now on how can we lift and bring everything together... Since we're very much in silos, maybe we haven't looked at the overall picture. There might be unnecessary things that we are doing [and] things we should do... In supply management, we started working very much in silos so we have experts [...]. They're very good at planning or they're good at purchasing.

P2. With a blended cost-efficient/responsive supply chain strategy, supply uncertainty is negatively related to firm performance. The level of decision-making centralisation within the organisational structure has a moderating effect.

CARE has multiple cross-functional teams working together to manage the frequent launches of new products, as well as cost-cutting projects. The high levels of internal coordination 
have helped it improve its operational performance. As noted by CARE's respondent: In the first two years [of cross-functional improvement projects] we achieved a good result because we decreased [by] more than one half the total amounts of the obsolete products. Furthermore, internal integration has facilitated improved collaboration with its key suppliers, which has resulted in successful product launches and the retention of good relationships with suppliers at minimum cost.

P3. With a cost-efficient supply chain strategy, demand uncertainty and innovation uncertainty are negatively related to firm performance. The level of internal coordination within the organisational structure has a moderating effect.

TOOL's brands compete against each other in the market due to the group's frequent acquisitions, lack of internal coordination and the individual management of supply chains. There is little internal integration between the different brands. The group relies on recruiting professional experts who work independently, and this has resulted in departmental silos that has kept internal cooperation at a minimum. It has also decreased the group's bargaining power during supplier negotiations. As noted by TOOL's respondent: This is a discussion that we're having, this is a line organisation so this is the extended management team, we have the different processes [...] and what we are discussing now is to form some kind of development management team. So this is our thinking to become more efficient.

$\boldsymbol{P} 4$. With a blended cost-efficient/responsive supply chain strategy, supply uncertainty is negatively related to firm performance. The level of internal coordination within the organisational structure has a moderating effect.

Stemming from these propositions, this paper puts forward a supply chain fit framework, developed for future testing (depicted in Figure 5), wherein the organisational structure is hypothesised to have a moderating effect on the relationship between supply chain fit and firm performance. As such, this study theorises that firm performance is dependent on a joint interaction between supply chain fit and organisational structure. Testing this framework can help in identifying the different combinations of supply chain strategy, design and organisational structure that can result in improved firm performance. 
Figure 5 - A framework for supply chain fit

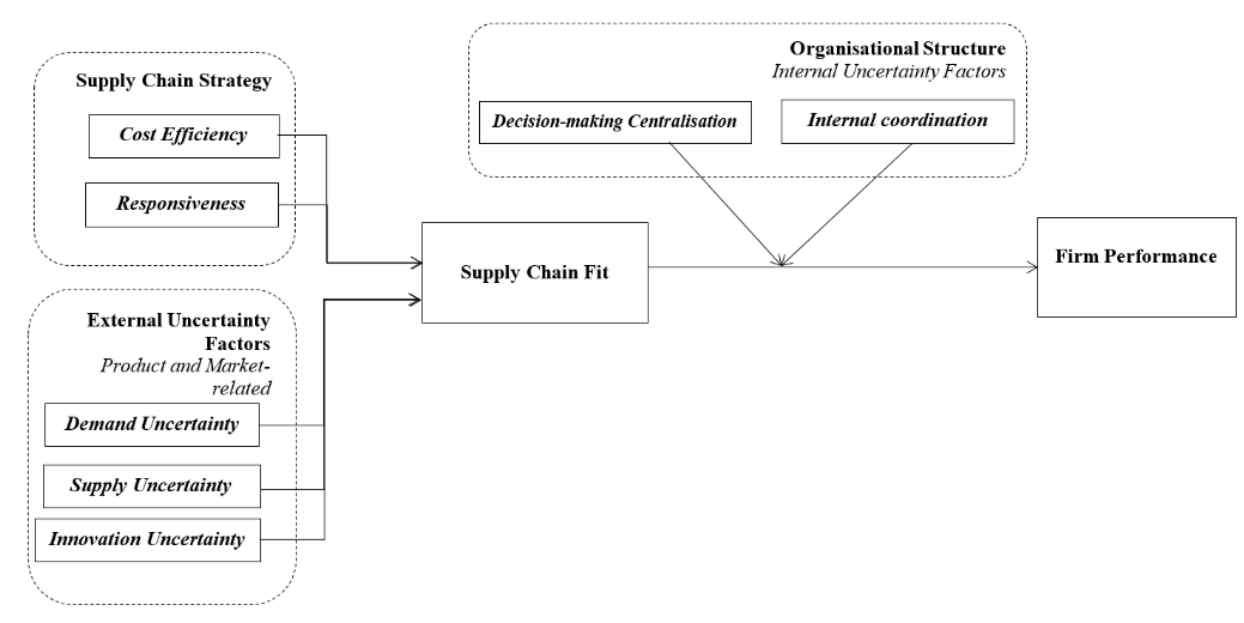

\section{Conclusion}

Supply chain fit research has often had an outward look in investigating environmental uncertainties. The main contributions of this study are its extension of our conceptual understanding and its provision of an empirical explanation of the interaction between organisational structure and the relationship between supply chain fit and firm performance.

This research found that the levels of decision-making centralisation and internal coordination can offset the negative impacts of a potential misfit, which was evident particularly in CARE. The analyses presented here augment the body of supply chain fit literature by exploring internal uncertainty factors, which were overlooked in Fisher's (1997) model (c.f. Gligor, 2017; Parjogo et al., 2018).

This paper contributes to supply chain fit theory and practice, firstly by identifying decision-making centralisation and internal coordination mechanisms as the internal uncertainty factors that are most relevant to supply chain fit research. This is because the authority of decision-making in individual firms affects the success of the entire supply chain, especially if the firm is a strong buyer, which was very evident in this research. Moreover, the level of internal integration and coordination within the organisational structure can facilitate/impede information sharing and the deployment of resources amongst the supply chain members, and can affect an organisation's position in negotiating with its supply base. 
Secondly, this paper puts forward four propositions to investigate the combination of decision-making centralisation, internal coordination and supply, demand and innovation uncertainties on the one hand, and firm performance on the other. These propositions can guide supply chain practitioners in recognising that variations in supply chain strategies alone do not necessarily lead to significant differences in performance. The focus instead needs to shift to the joint interaction between the combination of supply chain strategy, product/market related uncertainties and organisational structure, which can lead to an improvement/deterioration in firm performance.

Thirdly, this study puts forward a conceptual framework for supply chain fit, hypothesising that the organisational structure has a moderating effect on the relationship between supply chain fit and firm performance. The outlined framework contributes to the supply chain fit literature by identifying further environmental conditions in which a supply chain fit (or lack thereof) can be realised. This analysis can be most useful to supply chain researchers and managers in organisations that are experiencing internal uncertainties and are facing environmental changes related to a changing supply chain landscape or their internal structures.

The analyses of this study need to be interpreted with respect to their context, also bearing in mind that supply chains are designed to support products with different characteristics and maturity levels in the market, which influences supply chain strategies and structures. A second limitation is that this study provides a snapshot of supply chains that have been operating for years, a snapshot taken at a critical transformation moment of these corporate groups, when they had just undergone changes to their top management and to their strategies. This static perspective may be regarded as limiting the present findings' transferability.

The findings support the initial assumption that businesses pay little attention to their internal environment in designing and strategising supply chains. A potential avenue for future research would be to collect quantitative performance data that allow the propositions and the conceptual framework to be tested empirically in order to reveal the possible supply chain fit combinations that leads to improved firm performance. 


\section{References}

Aguinis, H., and Solarino, A. M. (2019), "Transparency and replicability in qualitative research: The case of interviews with elite informants" Strategic Management Journal. (Early View March 2019); pp.1-25.

Buttermann, G., Germain, R., and Iyer, K.N.S. (2008), "Contingency theory 'fit as gestalt': an application to supply chain management", Transportation Research PART E, Vol. 44 No. 6, pp. 955-969.

Child, J. (1972), “Organizational structure, environment and performance: The role of strategic choice", Sociology, Vol. 6 No. 1, pp. 1-22.

Chopra, S. and Meindl, P. (2007), Supply Chain Management: Strategy, Planning, and Operation. $3^{\text {rd }}$ ed., Pearson Prentice Hall, Upper Saddle River, NJ.

Christensen, M. and Knudsen, T. (2010), "Design of Decision-Making Organizations", Management Science, Vol. 56 No. 1, pp. 71-89.

Christopher, M. (2011), Logistics and Supply Chain Management, $4^{\text {th }}$ ed., Pearson, Great Britain

Daugherty, P. J., Chen, H., and Ferrin, B. G. (2011), "Organizational structure and logistics service innovation." The International Journal of Logistics Management, Vol. 22 No.1, pp.26-51.

Defee, C., and Stank, T. P. (2005), "Applying the strategy-structure-performance paradigm to the supply chain environment." The International Journal of Logistics Management, Vol. 16 No. 1, pp.28-50.

DiMaggio, P. J., and Powell, W. W. (1983), "The iron cage revisited-Institutional isomorphism and collective rationality in organizational fields", American Sociological Association Vol 48, April: pp. 147-160.

Doty, D. H., Glick, W. H., and Huber, G. P. (1993), "Fit, equifinality, and organizational effectiveness: A test of two configurational theories", Academy of Management journal, Vol.36 No.6, pp.1196-1250.

Drazin, R., and Van de Ven, A. H. (1985), "Alternative forms of fit in contingency theory", Administrative Science Quarterly, 514-539.

Eva, N., Sendjaya, S., Prajogo, D., Cavanagh, A., and Robin, M. (2018), "Creating strategic fit: Aligning servant leadership with organizational structure and strategy." Personnel Review, Vol.47 No.1, pp.166-186.

Farahani, R.Z., Shabnam, R., Drezner, T. and Fallah, S. (2014), Competitive supply chain network design: An overview of classifications, models, solution techniques and applications. Omega, Vol.45 (June 2014), pp.92-118. 
Fisher, M.L. (1997), "What is the right supply chain for your product?", Harvard Business Review, Vol.75 No.2, pp.105-116

Flynn, B. B., Huo, B., and Zhao, X. (2010), "The impact of supply chain integration on performance: A contingency and configuration approach", Journal of Operations Management, Vol. 28 No.1, pp.58-71.

Flyvbjerg, B. (2001), Making Social Science Matter: Why Social Inquiry Fails and how it can succeed Again. Cambridge: Cambridge University Press.

Flyvbjerg, B. (2011), “Case Study” in Norman K. Denzin and Yvonna S. Lincoln, eds., The Sage Handbook of Qualitative Research, $4^{\text {th }}$ ed., Thousand Oaks, CA: Sage, Chapter 17, pp. 301-316.

Fry, L. W., and Smith, D. A. (1987), "Congruence, contingency, and theory building" Academy of Management Review, Vol.12 No.1, pp.117-132.

Gambi, L.D.N., Boer, H., Gerolamo, M.C., Jørgensen, F. and Carpinetti, L.C.R., (2015), "The relationship between organizational culture and quality techniques, and its impact on operational performance" International Journal of Operations \& Production Management, Vol.35 No.10, pp.1460-1484

Gammeltoft, P., Filatotchev, I., and Hobdari, B. (2012), "Emerging multinational companies and strategic fit: a contingency framework and future research agenda." European Management Journal, Vol. 30 No. 3, pp. 175-188.

Gligor, D. M. (2016), “The Role of Supply Chain Agility in Achieving Supply Chain Fit.” Decision Sciences, Vol. 47 No.3, pp.524-553.

Gligor, D. M. (2017), "Re-Examining Supply Chain Fit: An Assessment of Moderating Factors." Journal of Business Logistics, Vol. 38 No.4, pp. 253-265.

Håkansson, H., and Snehota, I. (1989), "No business is an island: the network concept of business strategy”, Scandinavian Journal of Management, Vol.5 No.3, pp.187-200.

Halinen, A., and Törnroos, J. Å. (2005), "Using case methods in the study of contemporary business networks", Journal of Business Research, Vol.58 No.9, pp.1285-1297.

Hallavo, V., (2015), "Superior performance through supply chain fit: a synthesis", Supply Chain Management: An International Journal, Vol.20 No.1, pp.71-82.

Kathuria, R., Maheshkumar, P. J., and Stephen, J. P. (2007), “Organizational alignment and performance: past, present and future”, Management Decision, Vol.45 No.3 pp.503-517.

Ketokivi, M., and Choi, T. (2014), "Renaissance of case research as a scientific method", Journal of Operations Management, Vol.32 No.5, pp.232-240. 
Khandwalla, P. N. (1972), "Environment and its impact on the organization", International Studies of Management \& Organization, Vol. 2 No.3, pp.297-313.

Kim, S. W. (2007), "Organizational structures and the performance of supply chain management." International Journal of Production Economics, Vol. 106 No.2, pp.323-345.

Kovács, G. and Spens, M. (2005), “Abductive reasoning in logistics research”, International Journal of Physical Distribution \& Logistics Management, Vol.35 No.2, pp.132 - 144

Lawrence, P. R. and Lorsch, J. W. (1967), Organization and Environment. Cambridge, MA: Harvard University.

Lee, H.L. (2002), “Aligning supply chain strategies with product uncertainties", California Management Review, Vol.44 No.3, pp.105-19

Melnyk, S. A., Narasimhan, R. and DeCampos, H. A. (2014), "Supply chain design: issues, challenges, frameworks and solutions", International Journal of Production Research, Vol.52 No.7, pp.1887-1896.

Meredith, J. (1998), "Building operations management theory through case and field research", Journal of Operations Management, Vol.16 No.4, pp.441-454.

Meyer, S. B., and Lunnay, B. (2013). "The application of abductive and retroductive inference for the design and analysis of theory-driven sociological research." Sociological research online, Vol.18 No.1, pp.1-11.

Miles, R. E., Snow, C. C., Meyer, A. D., and Coleman, H. J. (1978), “Organizational strategy, structure, and process" Academy of management review, Vol. 3 No. 3, pp.546-562.

Miller, D. (1987), “The genesis of configuration”, Academy of Management Review, Vol.12 No.4, pp.686-701.

Mintezberg, H. (1979), The Structuring of Organisations. New Jersey, Prentice-Hall.

Morita, M., Machuca, J. A., Flynn, E. J., and de los Ríos, J. L. P. (2015), “Aligning product characteristics and the supply chain process-a normative perspective." International Journal of Production Economics, Vol.161, pp.228-241.

Nahm, A. Y., Vonderembse, M. A., and Koufteros, X. A. (2003), "The impact of organizational structure on time-based manufacturing and plant performance." Journal of operations management, Vol.21 No.3, pp.281-306.

Parthasarthy, R. and Sethi, S.P. (1992), "The impact of flexible automation on business strategy and organizational structure", Academy of Management Review, Vol. 17 No. 1, pp. 86-111.

Patton, M. (1990), Qualitative Evaluation and Research Methods. Beverly Hills, CA: Sage. 
Prajogo, D., Mena, C., and Nair, A. (2018), "The fit between supply chain strategies and practices: A contingency approach and comparative analysis." IEEE Transactions on Engineering Management, Vol.65 No.1, pp.168-180.

Rojo, A., Llorens-Montes, J., and Perez-Arostegui, M. N. (2016) "The impact of ambidexterity on supply chain flexibility fit." Supply Chain Management: An International Journal, Vol. 21 No.4, pp. 433-452.

Rozeboom, W. W. (1997), Good science is abductive, not hypothetico-deductive. What if there were no significance tests, (Eds.) Harlow, Lisa L., Mulaik, Stanley A., and Steiger, James H. 1997. New Jersey: Erlbaum. Extract. pp. 366-391.

Qi, Y., Zhao, X., and Sheu, C. (2011), "The impact of competitive strategy and supply chain strategy on business performance: the role of environmental uncertainty." Decision Sciences, Vol.42 No.2, pp.371-389.

Qi, Y., Huo, B., Wang, Z., and Yeung, H. Y. J. (2017). "The impact of operations and supply chain strategies on integration and performance." International Journal of Production Economics, Vol.185, pp.162-174.

Selldin, E. and Olhager, J., (2007), "Linking products with supply chains: testing Fisher's model”, Supply Chain Management: An International Journal, Vol.12 No.1, pp.42-51.

Sousa, R. and Voss, C. (2008), "Contingency research in operations management practices", Journal of Operations Management, Vol.26 No.6, pp. 697-713

Stock, G. N., Greis, N. P., and Kasarda, J. D. (1998), "Logistics, strategy and structure: a conceptual framework." International Journal of Operations \& Production Management, Vol. 18 No.1, pp.37-52.

Stock, G. N., Greis, N. P., and Kasarda, J. D. (2000), "Enterprise logistics and supply chain structure: the role of fit." Journal of Operations Management, Vol.18 No.5, pp.531-547.

Treiblmaier, H. (2018), “Optimal levels of (de)centralization for resilient supply chains", International Journal of Logistics Management, Vol. 29 No. 1, pp. 435-455.

Van de Ven, Andrew H., and Drazin, R. (1985) "The concept of fit in contingency theory." In Barry M. Staw and L. L. Cummings (eds.), research in Organizational Behavior, 7: pp.333-365. Greenwich, CT: JAI Press.

Van de Ven, Andrew H., Ganco, M., Hinings, C.R. (2013), "Returning to the Frontier of Contingency Theory of Organizational and Institutional Designs" The Academy of Management Annals, Vol. 7, No. 1, pp.393-440. 
Venkatraman, N. (1989), "The concept of fit in strategy research: toward verbal and statistical correspondence", Academy of Management Review, Vol.14 No.3, pp.423-444.

Wagner, S.M., Grosse-Ruyken, P.T. and Erhun, F. (2012), "The link between supply chain fit and financial performance of the firm", Journal of Operations Management, Vol. 30 No. 4, pp.340-353.

Yin, R.K., (2014), Case Study Research: Design and Methods, $5^{\text {th }}$ ed., Sage Publications Inc., Thousand Oaks, CA.

Zajac, E. J., Kraatz, M. S., and Bresser, R. K. (2000), "Modeling the dynamics of strategic fit: A normative approach to strategic change" Strategic management journal, Vol. 21 No. 4, pp.429-453.

Zheng, W., Yang, B., and McLean, G. N. (2010), "Linking organizational culture, structure, strategy, and organizational effectiveness: Mediating role of knowledge management", Journal of Business Research, Vol.63 No.7, pp.763-771. 